\title{
KAJIAN PENGGUNAAN VAKTOR (VAKUM EVAPORATOR) DALAM MEMPERTAHANKAN KANDUNGAN VITAMIN DAN ANTIOKSIDAN PADA MINUMAN SERBUK
}

\author{
Faidliyah Nilna Minah*, Siswi Astuti \\ Jurusan Teknik Kimia, Fakultas Teknologi Industri ITN Malang 65145 \\ *Author Utama, email: nilnaminah@yahoo.com \\ Co-author 1, email: siswiastuti@yahoo.com
}

\begin{abstract}
Instant Beverages are a food requirement that is difficult to separate from human life in this millennium. However, because human needs for fluids are far more than food, it is very important to pay attention to every food and beverage product consumed. Based on data from the Ministry of Health of the Republic of Indonesia, more than 5\% of Indonesia's population consumes various types of ready-to-drink drinks (instant). The still high debate about the negative impact of instant drinks, it is very important to standardize the quality of instant drinks on the market today. Related to this, the process of making tomato instant powder drinks has been optimized using the vacuum evaporator method with variations in temperature, time and filler in the evaporation process. Each product produced is analyzed for the content of vitamins $C$ and antioxidants. The vacuum evaporator is used to maintain the quality of the vitamins and antioxidants in powder drinks. The quality of instant powder drinks is improved by varying the drying temperature $\left(50-70^{\circ} \mathrm{C}\right)$, and variations in the drying time of products (3 - 7 hours). To obtain a granule formation, a mixture of sucrose, dextrin and tween 80 with a specific composition was used as a filler. The results showed that the vitamin $C$ content can be maintained high on drying for 7 hours with a low temperature, which is $50{ }^{\circ} \mathrm{C}$, with a value of $65,17 \mathrm{mg} / 100 \mathrm{~g}$. In contrast, the highest total $I C_{50}$ antioxidant activity $(24.10 \mathrm{mg} / \mathrm{ml})$ was obtained in the drying process for 3 hours using a temperature of $70^{\circ} \mathrm{C}$. The results of this study are expected to be a reference for determining parameters in vacuum evaporator designs equipped with packaging, so that it becomes a reference for home industries to produce healthy and nutritious instant drinks, namely instant powder drinks rich in vitamins and antioxidants, in accordance with SNI Standards and BPOM.
\end{abstract}

Keywords:Instant Powder Drink, Vitamins, Antioxidants, Vacuum evaporator

\begin{abstract}
ABSTRAK
Minuman Instan menjadi kebutuhan pangan yang sulit dipisahkan dari kehidupan manusia di Era millineum ini. Namun, karena kebutuhan manusia akan cairan yang jauh lebih banyak dibandingkan makanan, menjadi sangat penting untuk memperhatikan setiap produk makanan dan minuman yang dikonsumsi. Berdasarkan data Departemen Kesehatan Republik Indonesia, lebih dari 5\% penduduk Indonesia mengkonsumsi berbagai jenis minuman siap saji (instan). Masih tingginya perdebatan akan dampak negatif minuman instan, sangatlah penting untuk melakukan standarisasi kualitas minuman instan yang beredar di pasaran saat ini. Terkait hal ini, telah dilakukan optimalisasi proses pembuatan minuman serbuk instan tomat menggunakan metode vakum evaporator dengan variasi suhu, waktu dan filler pada proses evaporasi. Tiap produk yang dihasilkan dianalisa kandungan vitamin $C$ dan antioksidannya. Vakum evaporator digunakan untuk menjaga kualitas kandungan vitamin dan antioksidan dalam minuman serbuk. Kualitas minuman serbuk instan ditingkatkan dengan melakukan variasi suhu pengeringan $\left(50-70^{\circ} \mathrm{C}\right)$, dan variasi waktu pengeringan produk (3 - 7 jam). Untuk mendapatkan bentukan granul, campuran sukrosa,dekstrin dan tween 80 dengan komposisi spesifik digunakan sebagai filler. Hasil penelitian menunjukkan bahwa kandungan vitamin $C$ dapat dipertahankan tetap tinggi pada pengeringan selama 7 jam dengan suhu rendah, yaitu $50{ }^{\circ} \mathrm{C}$, dengan nilai sebesar 65,17 mg/100 g. Sebaliknya, total kadar aktivitas antioksidan IC 50 tertinggi $(24,10 \mathrm{mg} / \mathrm{ml})$ didapatkan pada proses pengeringan selama 3 jam menggunakan suhu $70^{\circ} \mathrm{C}$. Hasil penelitian ini diharapkan dapat menjadi rujukan untuk penentuan parameter dalam rancang-bangun vakum evaporator yang dilengkapi dengan pengemas, sehingga menjadi acuan bagi home industri untuk memproduksi minuman instan yang sehat dan bergizi yaitu minuman serbuk instan yang kaya vitamin dan antioksidan, sesuai dengan Standart SNI dan BPOM.
\end{abstract}

Kata Kunci:Minuman Serbuk Instan, Vitamin, Antioksidan, Vakum evaporator 


\section{PENDAHULUAN}

Indonesia merupakan salah satu negara yang memiliki potensi besar dalam bidang pertanian.Iklimnya yang tropis dengan curah hujan yang tinggi sepanjang tahun serta tanah yang subur, memungkinkan tumbuhnya berbagai jenis tanaman. Buah-buahan dan sayur-sayuran adalah salah satu produksi pertanian yang potensial untuk dipasarkan karena peranannya yang strategis antara lain sebagai bahan sumber gizi dan vitamin. Hampir semua buah-buahan dan sayursayuran dapat tumbuh dengan subur di negara Indonesia, yang diantaranya adalah tomat.

Tomat termasuk salah satu makanan yang menyehatkan.Tomat mengandung sejumlah nutrisi yang penting bagi tubuh. Tomat mentah mengandung vitamin $\mathrm{A}, \mathrm{B} 6, \mathrm{C}$, dan K. Selain itu, tomat juga mengandung folat, tiamin, niasin, magnesium, fosfor, kalium, dan tembaga. Tomat juga mampu menyediakan $7 \%$ jumlah asupan serat harian yang disarankan dan memiliki kandungan air relatif tinggi.

Tomat sangat bermanfaat untuk melindungi tubuh dari berbagai penyakit seperti jantung, stroke, dan hipertensi.Tomat membuat kulit sehat dan indah. Vitamin $\mathrm{K}$ dan kalsium dalam tomat sangat baik untuk memperkuat dan memperbaiki tulang. Likopen dalam tomat diketahui dapat meningkatkan massa tulang, sehingga dapat mencegah osteoporosis.Tomat juga memiliki kandungan antioksidan yang baik untuk kesehatan.
Antioksidan merupakan senyawa yang dapat mencegah bahaya akibat reaksi oksidasi.Senyawa ini berfungsi untuk menghambat penyakit degeneratif sepeti kanker, jantung, peradangan dan penuaan dini.Menurut Langseth [1] seperti yang dikutip oleh Slamet [2], terdapat beberapa jenis molekul kecil yang tidak dapat disintesis dalam tubuh, namun diperlukan sebagai antioksidan untuk melawan radikal bebas. Antioksidan akan merangsang respon imun tubuh sehingga mampu menghancurkan radikal bebas, mempertahankan kelenturan pembuluh darah, mempertahankan besarnya jaringan otak, dan mencegah kanker. Besarnya kemanfaatan antioksidan telah mendorong banyak peneliti untuk mengangkat potensi bahan alami dengan kandungan antioksidan untuk dapat dimanfaatkan dalam sajian lebih praktis dan mudah.

Menurut data BPS [3], tomat merupakan komoditas holtikultura yang laju produktivitasnya menempati posisi kedua setelah bawang merah, dimana diketahui laju produktivitas tomat mencapai $6.9 \%$. Data Departemen Pertanian[4] menunjukkan bahwa tingkat produktivitas tomat di Indonesia tahun 2007-2011 secara berurutan ialah 12,33 ton $/ \mathrm{Ha}, 13,66$ ton $/ \mathrm{Ha}, 15,27$ ton/ $\mathrm{Ha}, 14,58$ ton $/ \mathrm{Ha}$, dan 16,65 ton/ $\mathrm{Ha}$.

Besarnya kebutuhan akan tomat telah memicu petani tomat untuk lebih memaksimalkan produksinya. Di California, kenaikan produtivitas tomat dari tahun 19602012 mencapai 95\%, seperti yang dipublikasikan oleh Daniel G [5]. Tidak hanya di Indonesia, tomat juga dibutuhkan oleh 
banyak negara lain di dunia, salah satunya untuk digunakan sebagai sumber vitamin $\mathrm{C}$ dan antioksidan (data.go.id). Kondisi ini memberikan peluang ekonomi yang besar bagi negara tropis seperti Indonesia untuk melakukan pengolahan pasca panen produk ini sehingga dapat meningkatkan masa simpannya.

Salah satu jenis pengolahan pasca panen yang dapat dilakukan untuk komoditas tomat adalah pengolahan menjadi minuman serbuk instan.Pengeringan merupakan tahapan penting dalam pembuatan minuman serbuk instan berbasis komoditas pertanian. Berdasarkan metode pengeringannya, terdapat sejumlah teknologi pengolahan pasca panen buah-buahan menjadi produk serbuk siap saji, yaitu tray dryer, spray dryer, foam mat drying, freeze dryer dan evaporator. [6],[7-8] telah melaporkan pembuatan minuman serbuk tomat menggunakan spray dryer, sedangkan [9] telah mempublikasikan pembuatan minuman serbuk buah tropis menggunakan metode freeze dryer. Sementara itu, [10] telah melaporkan pembuatan tomat serbuk menggunakan metode foam mat drying.

Untuk mendapatkan metode pengeringan yang dapat mempertahankan kualitas nilai gizi dan kandungan antioksidan buah tomat, pada penelitian ini dievaluasi pemanfaatan metode pengeringan alternatif, yaitu vaktor (vakum evaporator). Untuk mengoptimalkan prosedur pengeringan yang dilaksanakan, penting untuk dioptimasi suhu dan waktu pengeringan produk pertanian.Sejalan dengan hal ini [11] telah melaporkan pembuatan manisan blimbing wuluh dengan hasil terbaik setelah pengeringan pada $90{ }^{\circ} \mathrm{C}$ selama 14 jam.Sri Rahayu [12] melaporkan pengeringan daun sambiloto menggunakan pengering vakum dengan temperatur $30-50{ }^{\circ} \mathrm{C}$ selama 10 210 menit.

Penelitian di atas menunjukkan bahwa suhu dan waktu pengeringan bahan menjadi faktor yang berpengaruh terhadap kualitas produk hasil pengeringan.Selain suhu dan waktu, penggunaan filler pada pembuatan minuman serbuk juga menjadi tahapan yang penting, sesuai dengan publikasi [13] yang mempublikasikan pembuatan minuman serbuk markisa menggunakan filler tween 80 dengan suhu pengeringan terbaik pada 50 ${ }^{\circ} \mathrm{C}$.Semua penelitian di atas menunjukkan bahwa pemrosesan menggunakan panas (thermal processing) sangatlah berpengaruh terhadap kualitas produk kering, seperti yang disampaikan oleh Veronika Dewanto [14].

Hasil yang bervariasi dari penelitian sebelumnya menjadi latar belakang dilakukannya pengembangan penelitian tentang serbuk minuman instan berbasis bahan alami, yaitu tomat. Penelitian ini dilakukan untuk mengetahui kondisi optimal terbaik pada pembuatan minuman serbuk instan tomat melalui pengujian kuantitatif, meliputi kadar vitamin C, aktivitas antioksidan, dan pengujian kualitatif kandungan logam pada produk minuman serbuk instan tomat yang dihasilkan. Untuk mengetahui pengaruh suhu dan waktu pengeringan, suhu pengeringan divariasikan pada $50,55,60,65$ dan $70^{\circ} \mathrm{C}$, sementarawaktu pengeringan divariasikan pada 3,5 dan 7 jam.Penelitian ini diharapkan dapat menghasilkan produk minuman serbuk instan tomat dengan kualitas yang memenuhi 
SNI 01-4320-1996.

\section{METODE PENELITIAN}

Material

Penelitian ini menggunakan bahan bahan seperti tomat segar, sukrosa dan tween 80

\section{Instrumentasi}

Peralatana yang digunakan adalah glass ware, pemotong, grinder, ayakan, pengering, dan vakum evaporator

\section{Prosedur}

\section{Persiapan Bahan}

Menyiapkan tomat segar yang berwarna merah dan matang, diblanching kemudian diekstraksi

\section{Ekstraksi}

Proses ekstraksi buah tomat dilakukan dengan menggunakan pelarut air pada suhu $30^{\circ} \mathrm{C}$

\section{Pembuatan Serbuk}

Buah tomat yang sudah diekstraksi kemudian dipekatkan dengan menggunakan alat vakum evaporator kemudian ditambahkan sukrosa dan tween 80 selanjutnya dikeringkan dengan menggunakan cabinet dryer.

\section{Sterilisasi UV}

Produk yang dihasilkan di sterilisasi dengan menggunkan stelisasi UV untuk menghambat pertumbuhan mikroba.

\section{Analisa}

Analisa produk yang dilakukan meliputi analisa kandungan vitamin $\mathrm{C}$, kadar aktivitas antioksidan, kadar air, kandungan logam pencemar dan jumlah mikroba.

Metode penelitian yang digunakan dalam penelitian ini adalah metode eksperimen dengan cara menganalisa data menggunakan metode grafik. Pembuatan minuman serbuk didapatkan melalui tahapan persiapan bahan, ekstraksi, penyerbukan,sterilisasi uv dan Analisa produk.

\section{HASIL DAN PEMBAHASAN}

Untuk mengetahui kualitas minuman serbuk instan tomat hasil optimasi pada penelitian ini, pada penelitian pendahuluan telah dilakukan analisa kandungan vitamin $\mathrm{C}$ dan aktivitas antioksidan bahan baku tomat segar yang nantinya akan digunakan sebagai kontrol atau kualitas pembanding dari produk minuman serbuk instan tomat dalam penelitian ini. Hasil Analisa pendahuluan menunjukkan kandungan vitamin $\mathrm{C}$ sebesar $12,14 \mathrm{mg} / 100 \mathrm{~g}$, sedangkan aktivitas antioksidan $\mathrm{IC}_{50}$ yang diperoleh adalah sebesar $221 \mathrm{mg} / \mathrm{ml}$. Pada Gambar 1 disajikan data kadar vitamin C produk minuman serbuk instan hasil pemrosesan menggunakan vakum evaporator.

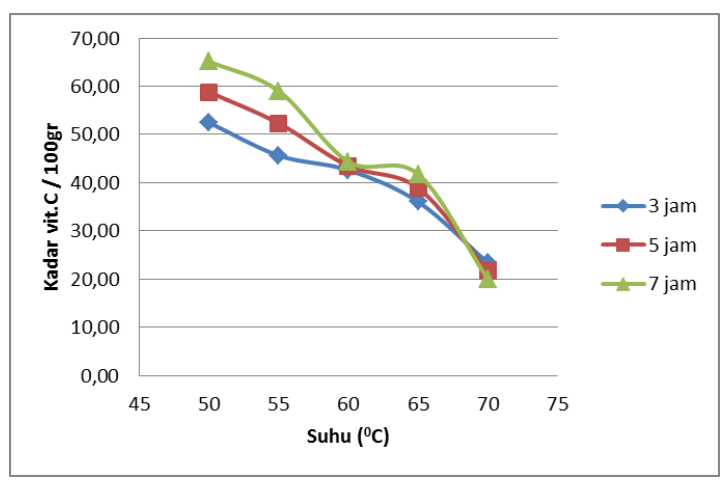

Gambar 1. Grafik kandungan vitamin $C$ pada berbagai variasi suhu dan waktu pengeringan

Pada gambar 1 tampak bahwa kandungan vitamin $\mathrm{C}$ semakin menurun seiring semakin meningkatnya suhu dan 
waktu pengeringan. Kondisi ini berlangsung hingga pengaplikasian suhu $55{ }^{\circ} \mathrm{C}$, dan mengalami peningkatan pada suhu $60{ }^{\circ} \mathrm{C}$, meski kembali mengalami penurunan pada pengaplikasian suhu pengeringan yang lebih tinggi $\left(65^{\circ} \mathrm{C}-70^{\circ} \mathrm{C}\right)$.

Tren perubahan kadar vitamin $\mathrm{C}$ produk minuman serbuk instan tomat seiring peningkatan suhu dan waktu pengeringan, khususnya pada pengaplikasian suhu $60^{\circ} \mathrm{C}$ diprediksikan berkaitan erat dengan masih tingginya heterogenitas spesifikasi bahan baku tomat yang digunakan. Sementara itu, tren penurunan kadar vitamin $\mathrm{C}$ pada suhu 50 ${ }^{\circ} \mathrm{C}-55^{\circ} \mathrm{C}$ dan $65^{\circ} \mathrm{C}-70^{\circ} \mathrm{C}$ sejalan dengan publikasi Budiyati [15] yang menyatakan adanya pengaruh suhu terhadap resistensi Vitamin $\mathrm{C}$, dimana resistensi vitamin $\mathrm{C}$ akan mengalami penurunan seiring peningkatan suhu perlakuan. Dengan demikian, pemrosesan buah tomat pada suhu rendah $\left(<60{ }^{\circ} \mathrm{C}\right)$ diharapkan akan meminimalisasi kerusakan vitamin Cdalam produk. Kadar vitamin $\mathrm{C}$ terbaik didapat pada produk yang diproduksi dengan suhu pengeringan $50{ }^{\circ} \mathrm{C}$ selama 7 jam.

Lebih lanjut, pada Gambar 2 tampak tren perubahan aktivitas antioksidan pada berbagai suhu dan waktu pengeringan.Menurut Wijaya [16] aktivitas antioksidan berbanding terbalik dengan harga $\mathrm{IC}_{50} . \mathrm{IC}_{50}$ adalah konsentrasi penghambatan setengah maksimal, yaitu ukuran efektivitas senyawa dalam fungsi biologis atau biokimia untuk menghambat, dimana semakin rendah nilai $\mathrm{IC}_{50}$, semakin tinggi aktivitas antioksidan.

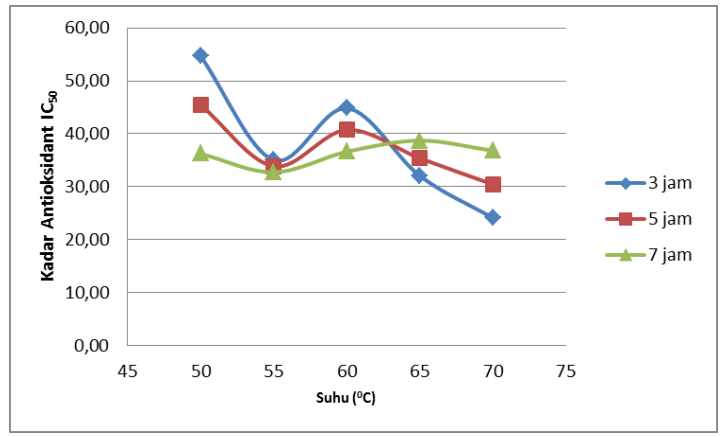

Gambar 2. Grafik kadar aktivitas antioksidan pada berbagai variasi suhu dan waktu pengeringan

Pada gambar 2 terlihat bahwa aktivitas antioksidan tertinggi didapatkan dari proses produksi minuman serbuk instan tomat yang menggunakan suhu pengeringan $70{ }^{\circ} \mathrm{C}$ selama 3 jam.

Sebagai produk pangan, minuman serbuk instan tomat harus memenuhi sejumlah persyaratan yang ditetapkan (SNI 01-3709-1995), dimana untuk produk pangan berbentuk serbuk, kadar air maksimal yang diperbolehkan adalah $10 \%$. Persyaratan tersebut telah terpenuhi pada proses pengeringan menggunakan suhu $50{ }^{\circ} \mathrm{C}$ selama 7 jam, $55^{\circ} \mathrm{C}$ dan $60{ }^{\circ} \mathrm{C}$ selama 5 dan 7 jam. Sementara pada suhu lebih tinggi, yaitu $65{ }^{\circ} \mathrm{C}$ dan $70{ }^{\circ} \mathrm{C}$, persyaratan kadar air terpenuhi ketika pengeringan dilakukan selama 3, 5 dan 7 jam. Hasil tersebut dapat diamati pada gambar 3 .

Selain kadar air, produk minuman serbuk instan tomat yang dihasilkan juga dianalisa secara kualitatif untuk mengetahui potensi cemaran logam. Hasil Analisa menunjukkan bahwa seluruh produk minuman serbuk instan tomat yang diproduksi 


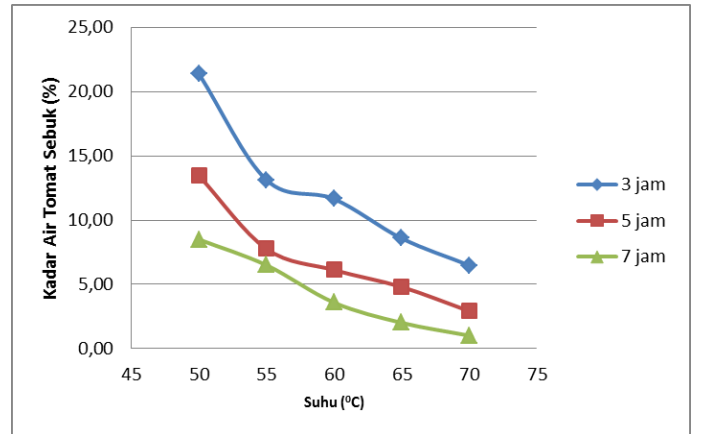

Gambar 3. Grafik kadar air pada berbagai variasi suhu dan waktu pengeringan

menggunakan variasi suhu dan waktu pengeringan menunjukkan hasil negatif.

Sementara untuk mengetahui potensi cemaran mikroorganisme, dilakukan analisa mikrobiologi pada seluruh produk minuman serbuk instan tomat yang dihasilkan. Hasil analisa menunjukkan bahwa cemaran mikroba yang ditemukan terkandung pada produk minuman serbuk instan tomat yang diproduksi dengan metode MPN menunjukkan hasil positif untuk Bacillus Subtillus, yaitu bakteri yang umum ditemukan di udara, air dan tanah. Bakteri ini dikenal bersifat anaerob.Namun demikian, hasil negatif ditunjukkan pada analisa kontaminasi oleh Escherecia coli. Terkait hal ini, persyaratan mutu pangan dalam bentuk serbuk mempersyaratkan kandungan Escherecia colimaksimal 103APM/g (SNI 013709-1995). Dengan demikian, dapat dikatakan bahwa produk minuman serbuk tomat yang dihasilkan pada penelitian ini telah memenuhi syarat mutu standar nasional.

\section{KESIMPULAN}

Proses pembuatan minuman serbuk tomat instan dipengaruhi oleh faktor-faktor seperti suhu pengeringan, waktu pengeringan. Produk minuman serbuk instan tomat dengan kualifikasi terbaik memiliki kandungan vitamin $\mathrm{C}$ sebesar $65,17 \mathrm{mg} / 100 \mathrm{~g}$ yang diperoleh pada proses produksi menggunakan suhu $50 \quad{ }^{\circ} \mathrm{C}$ dan waktu pengeringan selama 7 jam dan aktivitas antioksidan pada nilai $I_{50}$ sebesar 24,10 $\mathrm{mg} / \mathrm{ml}$, yang diperoleh pada proses produksi menggunakan suhu $70{ }^{\circ} \mathrm{C}$ dan waktu pengeringan selama 3 jam . Secara keseluruhan Hasil terbaik diperoleh pada optimalisasi proses pada kondisi suhu pengeringan $50^{\circ} \mathrm{C}$ dan waktu pengeringan selama 7 jam. Dimana Produk tersebut mengandung vitamin $\mathrm{C}$ tertinggi, kandungan aktivitas antioksidan yang juga tinggi, kadar air sesuai $\mathrm{SNI}$, dan hasil negatif terhadap uji cemaran logam serta mikroba

\section{UCAPAN TERIMAKASIH}

Kementrian Riset dan Teknologi Pendidikan Tinggi (Kemenristek Dikti) yang telah memberikan dana penelitian, dan Institut Teknologi Nasional (ITN) Malang, yang telah menyediakan sarana dan prasarana penelitian

\section{DAFTAR PUSTAKA}

[1] Langseth, L.. Antioxidants and Their Effect on Health. Essentials of Functional Foods, pp 303317. 2000.

[2] Slamet, Y. Formulasi Minuman Fungsional untuk Kelompok Gizi Khusus dari Kecambah Kacang Hijau (Phaeseolus radiatus, Linn) dan sari jahe (Zingiber officinalle Roseoe)[skripsi]. Bogor : Fakultas Teknologi Pertanian, Institut Pertanian Bogor. 2005.

[3] Badan Pusat Statistik. Statistik Indonesia.http://www.bps.go.id. Jakarta. 2011.

[4] Departemen Pertanian. Produktivitas Tomat Menurut Provinsi: 2007-2011. http://www.deptan.go.id/.../horti/pdfATAP2011/prodv-tomat.pdf. 2012.

[5] Daniel Geisseler and william, Production of processing tomatoes in california, Fertilizer research and education program. 2013. 
[6] Firotin dkk. Pembuatan Bubuk sari Buah Tomat dengan Metode Spray Drying Kajian dari pH Awal, Konsentrasi Dekstrin, Tween 80 dan Lama Penyimpanan. Balai Pengkajian Teknologi Pertanian (BPTP) NTB. Fakultas Teknologi Hasil Pertanian, UNIBRAW. 2013.

[7] Chaovanalikit dkk, Anthocyanin and total phenolics content of mangosteen and effect of processing on quality of mangosteen products, international food research journal 19(3). 2012.

[8] Phisut. Spray drying technique of fruit juice powder, some factors influencing the properties of product, international food research journal 19(4):12971306. 2012.

[9] Shofian. Pengaruh Penambahan Maltodekstrin pada Pengolahan Minuman Serbuk Sirsak terhadap Aktivitas Antioksidan. Universitas Pendidikan Indonesia.2011.

[10] Kamsiati, E. 'Pembuatan bubuk sari buah tomat(Licopersicon esculentum Mill.) dengan metode foam-matdrying', J. Teknol. Pert., vol. 7, no. 2, hlm. 113-9. 2006.

[11] Fitriani, Shanti. Pengaruh Suhu dan Lama Pengeringan terhadap Beberapa Mutu Manisan Belimbing Wuluh (Averrhoa bilimbi L) Kering. Agricultural Science and Technology Journal. Vol 7, No 01. 2008.
[12] Sri Rahayu, Konstanta laju pengeringan daun sambiloto menggunakn pengering tekanan rendah, Jurnal rekayasa proses vol 2 no 1, Yogya. 2008.

[13] Susanti, Yesi I., Putri, Widya D. R. Pembuatan Minuman Serbuk Markisa Merah (Passiflora edulis f. edulis Sims)(Kajian Konsentrasi Tween 80 dan Suhu Pengeringan). Jurnal Pangan dan Agroindustri. Vol 2, No 3. 2014.

[14] Veronika D, Thermal processing enhances the nutritional value of tomatoes by increasing total antioxidant activity, Jounal Agricultural and food chemistry, 50, 3010-3014. 2002.

[15] Budiyati C.S dkk. Pengaruh suhu terhadap Kadar Vitamin C pada Pembuatan Tepung Tomat< Prosiding Seminar Nasional Rekayasa Kimia dan Proses, 2004, ISSN:1411-4216. 2004.

[16] Wijaya, L. S., Widjanarko, S. B., dan Susanto, T. Ektraksi dan Karakterisi Pigmen dari Kulit Buah Rambutan (Nephelium Lappaceum). Var. Binjai, Biosain, Vol 1. 2001. 